\title{
A Single-Center, 10-Year Retrospective Study on Surgical Treatment and Prognosis Analysis of Differentiated Thyroid Carcinoma with Spinal Metastasis
}

This article was published in the following Dove Press journal:

Cancer Management and Research

\author{
Shuzhong Liu',* \\ Xi Zhou ${ }^{1, *}$ \\ An Song ${ }^{2}$ \\ Siyuan Yao' \\ Muchuan Wang' \\ Tong Niu' \\ Chengao Gao' \\ Zhen $\mathrm{Huo}^{3}$ \\ Yong Liu $\mathbb{D}^{1, *}$ \\ Yipeng Wang ${ }^{1, *}$
}

'Department of Orthopaedic Surgery, Peking Union Medical College Hospital, Peking Union Medical College and Chinese Academy of Medical Sciences, Beijing, People's Republic of China; ${ }^{2}$ Department of Endocrinology, Key Laboratory of Endocrinology, National Health and Family Planning Commission, Peking Union Medical College Hospital, Chinese Academy of Medical Science \& Peking Union Medical College, Beijing, People's Republic of China; ${ }^{3}$ Department of Pathology, Peking Union Medical College Hospital, Chinese Academy of Medical Science \& Peking Union Medical College, Beijing, People's Republic of China

*These authors contributed equally to this work

Correspondence: Yong Liu; Yipeng Wang Department of Orthopaedic Surgery, Peking Union Medical College Hospital, Peking Union Medical College and Chinese Academy of Medical Sciences, No. I Shuaifuyuan Wangfujing, Beijing 100730, People's Republic of China Email liuyong_pumch@।63.com; ypwang_pumch@I63.com
Objective: Metastatic spinal differentiated thyroid carcinoma (MSDTC) is relatively rare in the clinic and often overlooked. The objective of the current study is to analyze the clinical characteristics and prognosis of patients with MSDTC who underwent surgical treatment to determine the prognostic factors that affect survival.

Methods: This study retrospectively analyzed the clinical data and postoperative follow-up results of MSDTC patients who underwent spinal surgery at the Orthopedic Department of Peking Union Medical College Hospital from January 2010 to January 2020. Clinical data and survival time were analyzed by Kaplan-Meier analysis.

Results: Eleven patients were included, and the average age was 58.3 years (range 37-74). The average time from the initial surgery to the discovery of spinal metastasis was 42.9 months (range 0-132), and the average follow-up time was 21.8 months (range 3-80). Progression was identified in seven patients, and 10 patients $(90.9 \%)$ died during the followup period. Kaplan-Meier analysis showed that extraosseous visceral metastasis $(p=0.012)$, revised Tokuhashi score $(\mathrm{p}=0.035)$, Tomita score $(\mathrm{p}=0.038)$, and surgical method $(\mathrm{p}=0.028)$ were associated with overall survival (OS). In addition, skeletal visceral metastasis $(p=0.017)$, revised Tokuhashi score $(p=0.028)$, Tomita score $(p=0.038)$, and surgical method $(\mathrm{p}=0.049)$ were associated with progression-free survival (PFS).

Conclusion: Surgical treatment is an effective method for treating MSDTC and leads to pain relief, restored function and increased spinal stability. Based on our single-center experience, extraosseous visceral metastasis, revised Tokuhashi score, Tomita score, and surgical methods may be potential prognostic factors for OS whilst visceral metastasis, revised Tokuhashi score, Tomita score, and surgical methods may be potential prognostic factors for PFS.

Keywords: adjuvant therapy, clinical features, differentiated thyroid carcinoma, postoperative survival, prognostic factors, spinal metastasis, surgical treatment

\section{Introduction}

Differentiated thyroid carcinoma (DTC) is one of the primary pathogenic tumors associated with the development of spinal metastases. ${ }^{1}$ DTC is the most common thyroid carcinoma representing $90 \%$ of cases overall, consisting of papillary carcinoma $(70-75 \%)$ and follicular carcinoma $(15-20 \%){ }^{2}$ The prognosis of patients with thyroid carcinoma is good, and the 10-year survival rate is around $90 \%$; 
however, the presence of distant metastases is related to a significant reduction in life expectancy. ${ }^{1}$ Indeed, up to $68 \%$ of thyroid carcinoma patients develop spinal metastases and the clinical prognosis of this group of patients is poor. ${ }^{3-7}$ The presence of metastatic spinal differentiated thyroid carcinoma (MSDTC) significantly increases the incidence of complications and mortality. According to reports, the median survival time for patients with MSDTC is 4.1 years. ${ }^{1,8}$ In addition, spinal metastases from thyroid carcinoma are 3-4 times more likely to cause spinal cord compression than metastatic tumors from breast or prostate cancer, and up to $13 \%$ of thyroid carcinoma patients may have pathological fractures resulting from spinal metastases. ${ }^{1,5,8}$

The treatment of MSDTC has evolved from surgery and radiation therapy to a multidisciplinary comprehensive treatment strategy, including spinal surgery, general surgery, radiotherapy, nuclear medicine and endocrinology. The main focus of treatment is usually to control the primary lesions rather than to treat metastatic spinal lesions, which may lead to a serious decline in quality of life. Although multiple studies have shown that surgical treatment is effective for MSDTC, the use of aggressive surgical resection and the prognostic characteristics of the disease remains controversial. ${ }^{9,10}$ Previous studies have evaluated the prognostic factors associated with systemic metastasis of thyroid carcinoma; however, there is still no specific research into factors that affect MSDTC patient survival. ${ }^{1,9,10}$ Therefore, the purpose of this study is to determine factors related to the postoperative survival of MSDTC patients after spinal surgery. This prognostic information will aid clinical decision-making because patients with better prognosis may require more active intervention, whilst patients with poor life expectancy can avoid excessively aggressive treatment. Here, we provide a clinical retrospective analysis of the treatment and prognosis of 11 patients with MSDTC who underwent spinal surgery.

\section{Patients and Methods}

We reviewed the clinical and prognostic data of all patients with MSDTC who underwent spinal surgery at the Orthopedic Department of Peking Union Medical College Hospital from January 2010 to January 2020. This study was approved by the institutional review committee of the Peking Union Medical College Hospital, Chinese Academy of Medical Sciences. All patients provided written informed consent. We studied potential factors related to progression-free survival (PFS, the interval between the date of spinal surgery and the progression of spinal lesions observed), and overall survival (OS, the interval between the date of spinal surgery and death due to disease or until the last follow-up).

We used data collected from the orthopedic spine tumor database of the Orthopedic Department of Peking Union Medical College Hospital. A retrospective review of clinical and radiological data was conducted including patient age, sex, initial diagnosis of thyroid carcinoma, histology of thyroid carcinoma, previous history of thyroid carcinoma resection, first metastasis diagnosis, first spinal cord metastasis diagnosis, duration of symptoms before spinal surgery, location of spinal metastasis, treatment methods (including radioactive iodine, chemotherapy, radiotherapy), preoperative Frankel score and Karnofsky performance score (KPS), preoperative pain score (assessed by visual analogue scale [VAS]), status of spinal disease before surgery, and surgical data (surgical methods, vertebral reconstruction and type, length and effect of fixation segments). Preoperative evaluation included X-rays, contrast-enhanced computed tomography (CT) scan of the spine, neck, thorax and abdomen, and contrastenhanced spine magnetic resonance imaging (MRI). Before surgery, bone scan and positron emission tomography-computed tomography (PET-CT) were used to verify bone metastasis and extraosseous metastasis to avoid overtreatment, especially for patients recommended to undergo total spinal resection. In addition to spinal metastases, the location of metastatic disease was classified as involving the lung, liver, brain, extraspinal bone, or other locations.

An individualized surgical plan was made for each patient according to the position of the lesion in the spine and the degree of spine and paraspinal disease burden. All 11 patients underwent surgical resection or biopsy of the primary tumor before spinal surgery and were pathologically diagnosed with DTC (6 cases of papillary thyroid carcinoma and 5 cases of follicular thyroid carcinoma). Radiological assessments (X-ray, CT, or MRI) were performed 3 and 6 months postoperatively, followed by periodic assessments every 6 months for the next 2 years, and then life-long assessments every year. PET-CT was recommended for detailed evaluation of patients with evidence of tumor progression. Follow-up data were collected from outpatient visits and telephone interviews. During the postoperative follow-up period, neurological function and pain were reassessed according to the VAS, Frankel and Karnofsky scoring systems. The follow-up 
period was defined as the time interval from the date of spinal surgery to the date of death or the last follow-up.

\section{Statistical Analysis}

The Kaplan-Meier method was used to analyze the basic clinical data of patients including sex, age, spinal metastasis site, Frankel score, KPS, spinal instability score (SINS), VAS, revised Tokuhashi score, Tomita score, urinary incontinence, fecal incontinence, spinal pathological fracture, primary tumor subtype, visceral metastasis, bone damage (osteolytic, osteogenic or mixed type), and postoperative survival rate estimate. Kaplan-Meier analysis was used to assess factors related to survival after spinal surgery. Statistical analysis was performed using IBM SPSS 23.0 statistical software (IBM Corp., Armonk, NY, USA) where $\mathrm{p}<0.05$ was considered statistically significant.

\section{Results}

During the study period, 11 consecutive patients with MSDTC received surgical treatment for spinal metastases, with a total of 13 operations. Table 1 lists the clinical characteristics of these patients. Our study included 1 male and 10 females, with an average age of 58.3 years (range 37-74). Local pain was the most common symptom and the average duration of preoperative symptoms was 9.0 months (range 1.5-36).

\section{Treatment Before Spinal Surgery}

Eleven patients underwent ultrasound preoperative biopsy without any complications. All pathological diagnoses were DTC, of which six cases $(54.5 \%)$ were papillary carcinoma and five cases $(45.5 \%)$ were follicular carcinoma. Ten of the eleven patients $(90.9 \%)$ received thyroid carcinoma resection (thyroidectomy) before spinal surgery. The average time from previous thyroid surgery to spinal metastasis was 42.9 months (range 0-132). Four patients $(36.7 \%)$ received radioactive iodine treatment before spinal surgery intervention, three patients (27.3\%) received radiotherapy to control the primary lesion and one patient $(9.1 \%)$ received chemotherapy. No recurrence or local progression was found before spinal surgery.

\section{The Location and Number of Spinal Metastases}

In our patient series, the most common spinal metastasis location was the lumbar spine (nine patients; 81.8\%). There were also five cases of thoracic spine involvement
(45.5\%), two cases of sacral involvement (18.2\%), and one case of cervical spine involvement (9.1\%). Five patients had a single spinal metastatic lesion whilst six patients had multiple segmental metastatic lesions. The largest burden of spinal metastatic disease involved five vertebral levels in one patient.

Most spinal lesions in this study showed osteolytic changes (10 cases) whereas only one case of osteogenic change was observed. Seven patients developed vertebral compression fractures whilst MRI showed that four patients had spinal cord compression and four patients had paravertebral extension. In addition, four patients had uncontrolled extraosseous visceral metastasis to the brain, liver or lungs before spinal surgery.

\section{Treatment and Follow-Up}

Table 2 shows clinical data of spinal metastasis in 11 patients with MSDTC. Prior to spinal surgery, nine patients (81.8\%) had normal neurological function (Frankel grade E) and two patients (18.2\%) had neurological defects (Frankel grade C). Surgical treatment was completed by the team of Professor Liu in our department, and a total of 13 surgical operations were performed. Five of these operations involved posterior tumor resection, spinal cord decompression, and titanium rod system spinal reconstruction (Figure 1) and the average blood loss during the operations was $900 \mathrm{~mL}$ (range 400-1600). Eight operations were minimally invasive bone cement percutaneous vertebroplasties (Figure 2) with average perioperative blood loss of $31.1 \mathrm{~mL}$ (range 20-50). There were no obvious complications during the perioperative period; therefore, the original treatment plans continued. For isolated spinal metastatic lesions, we prefer total resection. Five patients in this study underwent open surgery which was supplemented with postoperative adjuvant therapy to maximize the removal of spinal metastatic disease and maximize the stability of the spine. During the 3-month follow-up period, the Frankel score in two patients with neurological defects improved by 1-2 grades. All 11 patients received bisphosphonate treatment after surgery. Postoperative immunohistochemical results supported the pathological diagnosis of MSDTC. In our series, six patients $(54.5 \%)$ had papillary thyroid cancer, and five patients $(45.5 \%)$ had follicular thyroid cancer. The average OS after surgery was 21.8 months (range 3-80), and the average PFS was 19.5 months (range 3-76). The 1 - and 2-year survival rate was $81.8 \%$ and $27.3 \%$, respectively. 
Table I Clinical Review of II Patients with Metastatic Spinal Differentiated Thyroid Carcinoma in Our Single Centre

\begin{tabular}{|c|c|c|c|c|c|c|c|c|c|}
\hline Patients & Operations & $\begin{array}{l}\text { Age } \\
(y), \\
\text { Sex }\end{array}$ & $\begin{array}{l}\text { Symptoms and } \\
\text { Signs }\end{array}$ & $\begin{array}{l}\text { Spinal } \\
\text { Metastases } \\
\text { Location }\end{array}$ & $\begin{array}{l}\text { Incomplete } \\
\text { Paralysis or } \\
\text { Paralysis }\end{array}$ & $\begin{array}{l}\text { Resection } \\
\text { of } \\
\text { Primary } \\
\text { Lesion }\end{array}$ & Surgery & $\begin{array}{l}\text { Adjuvant } \\
\text { Treatment }\end{array}$ & $\begin{array}{l}\text { Perioperative } \\
\text { Complications }\end{array}$ \\
\hline I & 1 & $37, \mathrm{~F}$ & Sacrococcygeal pain & Sacrum & No & Yes & $\begin{array}{l}\text { Percutaneous } \\
\text { vertebroplasty }\end{array}$ & $\begin{array}{l}{ }^{|3|} \mid, \\
\text { radiotherapy }\end{array}$ & None \\
\hline 2 & 2 & $48, F$ & Back pain & T6 & No & Yes & $\begin{array}{l}\text { Posterior } \\
\text { decompression, } \\
\text { tumor resection } \\
\text { as well as } \\
\text { internal fixation }\end{array}$ & $\begin{array}{l}{ }^{|3|} \mid, \\
\text { radiotherapy }\end{array}$ & None \\
\hline 3 & 3 & $64, F$ & Back pain & T4-7, L2 & No & No & $\begin{array}{l}\text { Percutaneous } \\
\text { vertebroplasty }\end{array}$ & I & None \\
\hline 4 & 4 & $56, F$ & $\begin{array}{l}\text { General weakness } \\
\text { and multiple bone } \\
\text { pain }\end{array}$ & L2, L3 & No & Yes & $\begin{array}{l}\text { Percutaneous } \\
\text { vertebroplasty }\end{array}$ & I & None \\
\hline 5 & 5 & $43, F$ & $\begin{array}{l}\text { Progressive back } \\
\text { pain, numbness and } \\
\text { decreased muscle } \\
\text { strength of bilateral } \\
\text { lower limbs, bowel } \\
\text { and bladder } \\
\text { disturbances }\end{array}$ & L2, L4 & $\begin{array}{l}\text { Incomplete } \\
\text { paralysis }\end{array}$ & Yes & $\begin{array}{l}\text { Posterior } \\
\text { decompression, } \\
\text { tumor resection } \\
\text { as well as } \\
\text { internal fixation }\end{array}$ & 1 & None \\
\hline 6 & 6 & 7I, F & Back pain & LI & No & Yes & $\begin{array}{l}\text { Percutaneous } \\
\text { vertebroplasty }\end{array}$ & I & None \\
\hline 7 & 7 & $59, F$ & Back pain & TIO & No & Yes & $\begin{array}{l}\text { Posterior } \\
\text { decompression, } \\
\text { tumor resection } \\
\text { as well as } \\
\text { internal fixation }\end{array}$ & I & None \\
\hline 8 & 8 & $61, F$ & Back pain & $\mathrm{L} 5, \mathrm{SI}$ & No & Yes & $\begin{array}{l}\text { Percutaneous } \\
\text { vertebroplasty }\end{array}$ & $\begin{array}{l}{ }^{|3|} \mid, \\
\text { radiotherapy, } \\
\text { chemotherapy }\end{array}$ & None \\
\hline \multirow[t]{3}{*}{9} & 9 & $62, F$ & Back pain & T3 & No & Yes & $\begin{array}{l}\text { Posterior } \\
\text { decompression, } \\
\text { tumor resection } \\
\text { as well as } \\
\text { internal fixation }\end{array}$ & I & None \\
\hline & 10 & $63, F$ & Back pain & T3, L5 & No & Yes & $\begin{array}{l}\text { Percutaneous } \\
\text { vertebroplasty }\end{array}$ & $|3| \mid$ & None \\
\hline & 11 & $64, F$ & Back pain & T3, L5 & No & Yes & $\begin{array}{l}\text { Percutaneous } \\
\text { vertebroplasty }\end{array}$ & 1 & None \\
\hline 10 & 12 & $\begin{array}{l}56 \\
M\end{array}$ & Back pain & $\begin{array}{l}\text { T9, TI2, L2, } \\
\text { L4 }\end{array}$ & No & Yes & $\begin{array}{l}\text { Percutaneous } \\
\text { vertebroplasty }\end{array}$ & I & None \\
\hline
\end{tabular}

(Continued) 
Table I (Continued).

\begin{tabular}{|l|l|l|l|l|l|l|l|l|}
\hline Patients & Operations & $\begin{array}{l}\text { Age } \\
\text { (y), } \\
\text { Sex }\end{array}$ & $\begin{array}{l}\text { Symptoms and } \\
\text { Signs }\end{array}$ & $\begin{array}{l}\text { Spinal } \\
\text { Metastases } \\
\text { Location }\end{array}$ & $\begin{array}{l}\text { Incomplete } \\
\text { Paralysis or } \\
\text { Paralysis }\end{array}$ & $\begin{array}{l}\text { Resection } \\
\text { of } \\
\text { Primary } \\
\text { Lesion }\end{array}$ & $\begin{array}{l}\text { Surgery } \\
\text { Treatment } \\
\text { Complications }\end{array}$ & $\begin{array}{l}\text { Perioperative } \\
\text { Pain, numbness and } \\
\text { decreased muscle } \\
\text { strength of bilateral } \\
\text { lower limbs, bowel } \\
\text { and bladder } \\
\text { disturbances }\end{array}$ \\
\hline 13 & $74, \mathrm{~F}$ & $\begin{array}{l}\text { Progressive back } \\
\text { C6, L4-5 }\end{array}$ & Incomplete \\
paralysis & Yes & $\begin{array}{l}\text { Posterior } \\
\text { decompression, } \\
\text { tumor resection } \\
\text { as well as } \\
\text { internal fixation }\end{array}$ & 1 \\
\hline
\end{tabular}

\section{Kaplan-Meier Analysis of Prognostic Factors}

Kaplan-Meier analysis showed that several factors significantly affected OS (Figure 3) and PFS (Figure 4) in patients with MSDTC. Extraosseous visceral metastasis $(\mathrm{p}=0.012)$, revised Tokuhashi score $(\mathrm{p}=0.035)$, Tomita score $(\mathrm{p}=0.038)$, and surgical method $(\mathrm{p}=0.028)$ were associated with OS whilst extraosseous visceral metastasis $(\mathrm{p}=0.017)$, revised Tokuhashi score $(\mathrm{p}=0.028)$, and surgical method $(\mathrm{p}=0.049)$ were associated with PFS. Different histological subtypes (papillary carcinoma and follicular carcinoma) also showed trends in OS but these were not statistically significant.

Age, sex, previous thyroidectomy, surgical spinal metastasis level, incubation period of primary systemic metastasis, number of spinal levels involved, initial spinal metastasis treatment, type of spinal metastasis bone changes, spinal cord compression, paravertebral extension, defecation and other multiple scoring systems did not affect OS or PFS.

\section{Discussion}

Thyroid carcinoma is divided into DTC (papillary carcinoma and follicular carcinoma, accounting for $90 \%$ of cases), poorly differentiated adenocarcinoma (medullary carcinoma, accounting for $5-10 \%$ of cases) and undifferentiated adenocarcinoma ( $<5 \%$ of cases). ${ }^{1,2,9,10}$ The 10 -year survival rate of patients with thyroid carcinoma is $80-95 \%$ whereas, after metastasis, the 10-year survival rate is only $40 \%$. Metastases from thyroid carcinoma occur in the lung $(50 \%)$, bone $(25 \%)$, the lung and bone $(15 \%)$ and other locations (10\%). ${ }^{1,2,9,10}$ Cases of MSDTC are relatively rare and patients generally have much longer survival and a better prognosis than patients with spinal metastases originating from other primary cancers. Orita et al reported that $3.7 \%$ of patients with DTC had bone metastases. ${ }^{11}$ The spinal metastases of thyroid carcinoma are mainly osteolytic lesions and once a bone-related event occurs, quality of life is significantly reduced, which is likely to affect the patient's clinical prognosis. Therefore, research into the occurrence and development of MSDTC, as well as prognostic characteristics and treatment methods is important for the optimal management of MSDTC. The focus of spinal surgeons is to control spinal metastases, improve quality of life, and minimize the risk of surgical intervention.

MSDTC lesions are common in the vertebral body (85\%), most commonly in the thoracic spine $(60-80 \%)$. Clinical symptoms include bone pain (59-83\%), spinal cord compression (28\%), and pathological fractures $(13 \%) .{ }^{12,13}$ PET-CT is the most commonly used detection method for determining whole body metastases and ${ }^{124}$ I-PET-CT is more targeted to bone metastases. ${ }^{14} \mathrm{CT}$ is used to determine spine stability whilst MRI is used to determine the relationship between the tumor and the spinal cord to guide the choice between radiotherapy and/or surgery. ${ }^{1,13}$ Orita et al showed that high-dose radioiodine therapy, which could also be related to surgical treatment, was correlated with better prognosis in patients with bone metastases from DTC whilst multiple organ metastases are linked with poor prognosis. ${ }^{11}$

There are a variety of treatments available for patients with MSDTC including surgical resection, percutaneous vertebroplasty, ${ }^{131} \mathrm{I}$, radiation therapy, chemotherapy, bisphosphonate treatment and other new therapies. ${ }^{1,9,10,15-18}$ The 2013 edition of the National Comprehensive Cancer Network (NCCN) instruction manual recommends five methods: surgical intervention, ${ }^{131} \mathrm{I}$ in vivo or in vitro radiotherapy, arterial embolism, 


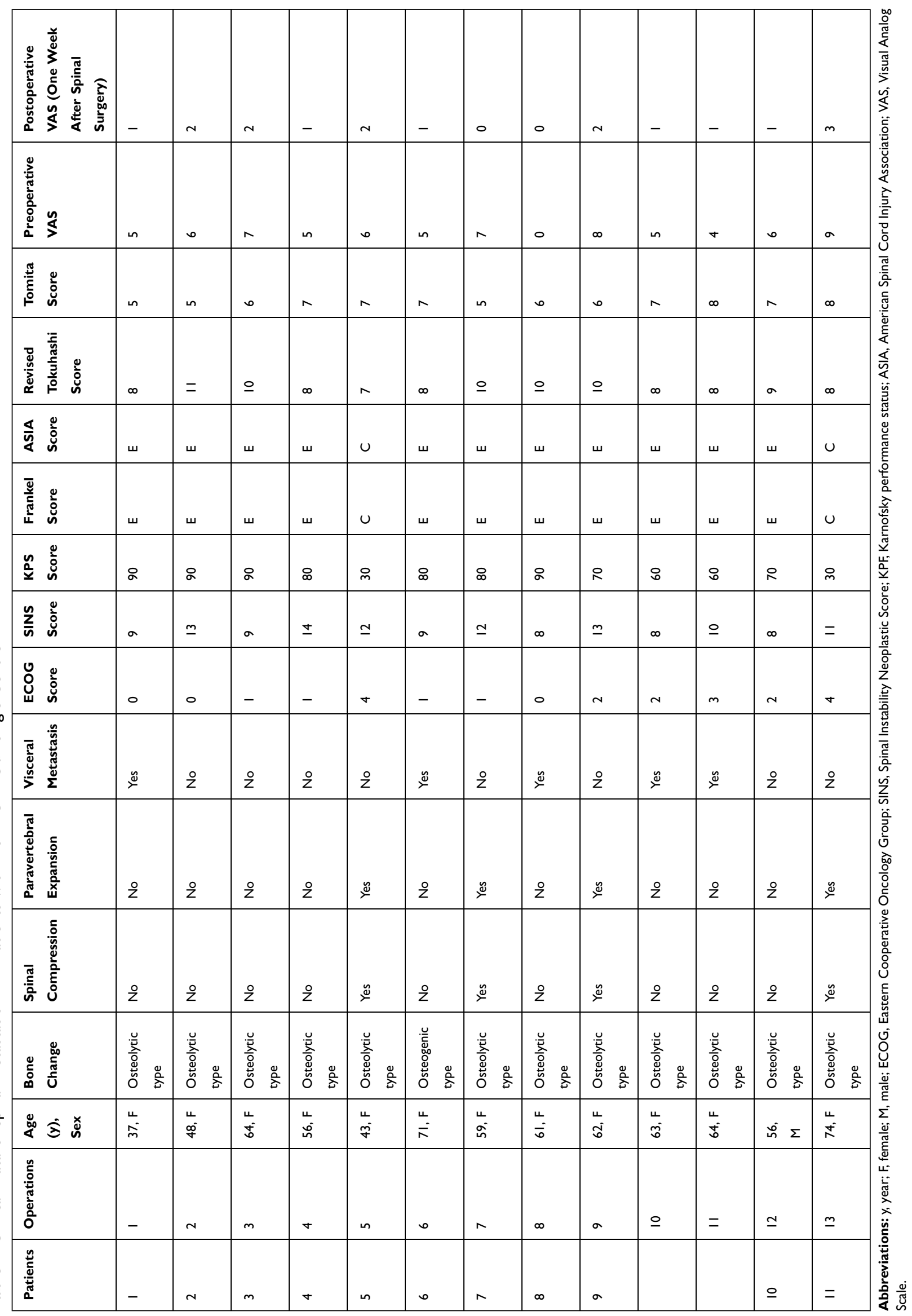



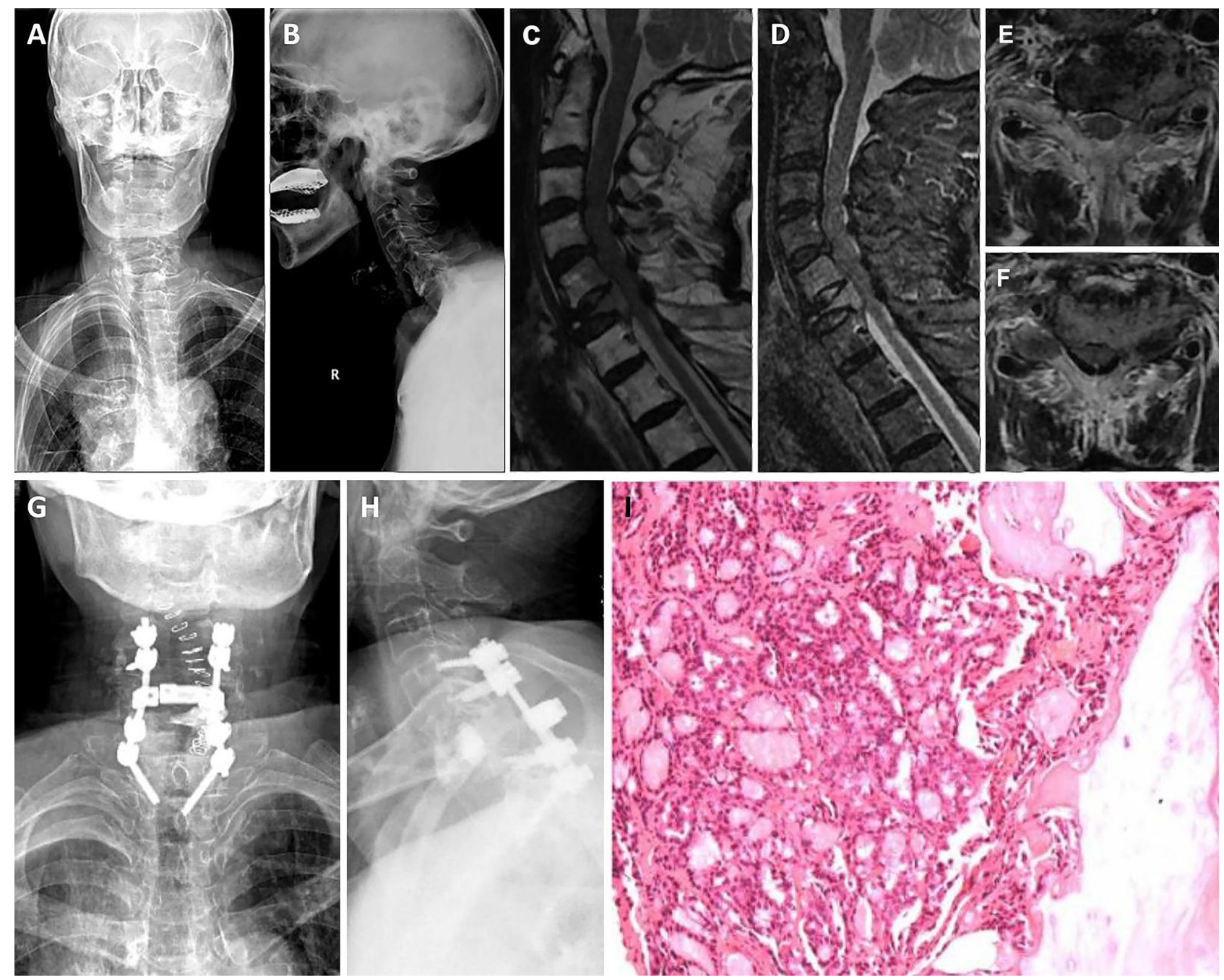

Figure I Radiographic and pathological images of a representative 74-year-old female patient (Case \#II). (A and B) Preoperative X-rays. (C-F) Preoperative sagittal and transverse MRI scan revealing vertebral metastases. ( $\mathbf{G}$ and $\mathbf{H}$ ) Postoperative X-rays of the cervical spine. (I) Microphotography showing significant nuclear pleomorphism with prominent nucleoli (H\&E, original magnification 100x).

bisphosphonates and targeted therapy. ${ }^{12}$ In recent years, percutaneous vertebroplasty has also been applied in this field. Patients with single spinal metastasis are mainly treated by surgery whereas personalized treatment plans are developed for patients with multiple spinal metastases/systemic metastases that include a combination of surgery, internal medicine and radiotherapy. ${ }^{1,9,10}$

Surgical intervention is necessary when pain intolerance, resistance to conservative treatment, vertebral compression fractures and segmental instability, failure to respond to chemotherapy and ${ }^{131} \mathrm{I}$ treatment, and progressive neurological deficits including paraplegia or quadriplegia occur. Spinal cord compression is more common in patients with spinal metastases from thyroid carcinoma, with an incidence of $28 \%$ compared with other types of spine metastasis such as those originating from prostate and breast cancer, which have an incidence of $10 \%$ and $8 \%$, respectively. ${ }^{1,5,19,20}$ The decision on whether to perform conservative or radical surgery in patients with spinal metastatic disease remains a very controversial topic and there are few studies that have evaluated large numbers of patients with MSDTC who undergo spinal surgery.

The indications for surgical treatment of MSDTC are as follows: (1) persistent pain; (2) single spinal metastasis; (3) insensitivity to other treatments; (4) presence of high-risk factors for pathological fractures and paraplegia; (5) occurrence of nerve damage; (6) pathological confirmation of diagnosis; (7) an expected survival time of more than 3 months. The purpose of surgical treatment is to remove as much of the spinal metastasis as possible, and the aim of palliative surgery is to reduce body pain and relieve nerve compression. Both procedures maintain or restore spinal stability. In 2011, the 

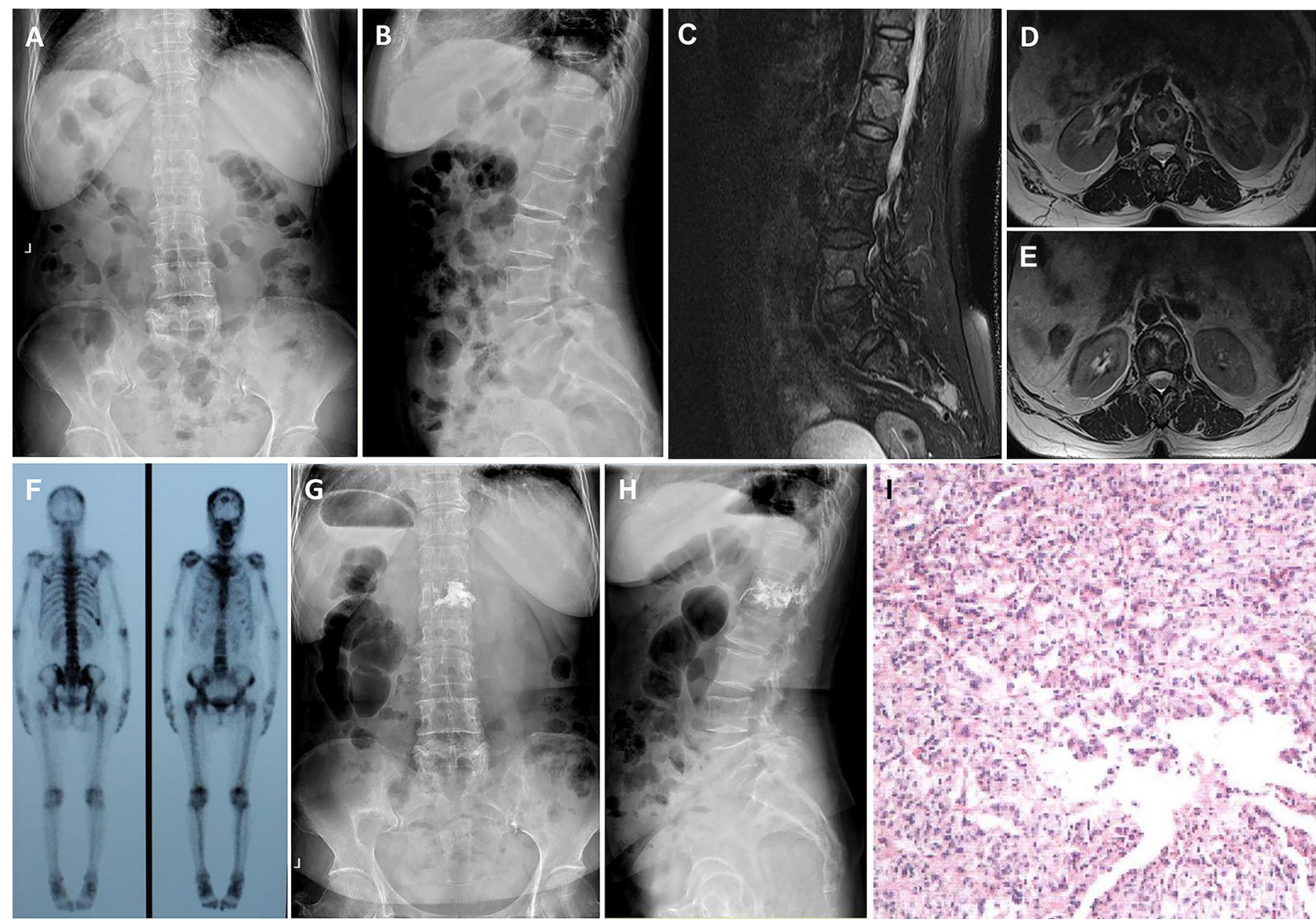

Figure 2 Radiographic and pathological images of a representative 7I-year-old female patient (Case \#6). (A and B) Preoperative X-rays. (C-E) Preoperative sagittal and transverse T2-weighted MRI scan revealing vertebral metastases. (F) Bone scan revealing multiple metastases of the spine. (G and $\mathbf{H}) \mathbf{X}$-ray images of the lumbar spine obtained postoperatively. (I) Microphotography showing significant nuclear pleomorphism with prominent nucleoli (H\&E, original magnification I00x).

Tomita team in Japan reported 24 patients with MSDTC, of which 14 patients underwent palliative resection. Reoperation occurred, on average, 41 months after the initial spinal operation. The postoperative local recurrence rate in these patients was $57 \%$, and the 5 -year survival rate was $63 \%$. Total en bloc spondylectomy (TES) was performed on the remaining 10 patients and the postoperative recurrence rate was $10 \%$ with a 5-year survival rate of $90 \%(\mathrm{P}<0.01)$, demonstrating that TES can effectively reduce local recurrence and improve the survival rate of patients with DTC. ${ }^{9}$ In 2013, a study reported a 7-year follow-up of 22 patients with MSDTC and showed that surgical resection could significantly improve nerve function and patient quality of life. ${ }^{10}$ Matsumoto et al reported on 8 patients who underwent total spinal resection due to thyroid metastasis and showed that all patients had an improved Frankel grade classification at the 1-year follow-up examination. $^{21}$

There is no international consensus on whether to choose open radical surgery or minimally invasive palliative surgery for spinal metastases..$^{1,9,10,22}$ Minimally invasive palliative surgery has a low risk and can relieve pain symptoms whereas radical surgery can obtain better local control and may be curative when combined with comprehensive treatment. However, radical surgery is difficult to perform, the risk to the patient is high and the reconstruction of spinal stability is complicated. PVP using bone cement can generate heat that makes tumor tissue necrotic, and also stabilizes micro-fractures to prevent vertebral body collapse and subsequent damage to nerve endings that in turn relieves pain. ${ }^{23}$ Indeed, Song et al retrospectively analyzed 8 patients with MSDTC treated with PVP combined with ${ }^{131}$ I and found that the postoperative bone pain symptoms of all patients were quickly relieved. ${ }^{24}$ However, the complication rate of PVP is 5-10\%, including mass bone cement leakage, infection, allergies and bleeding.

${ }^{131} \mathrm{I}$ radiation therapy is the primary treatment method for patients with bone metastases from DTC and is 

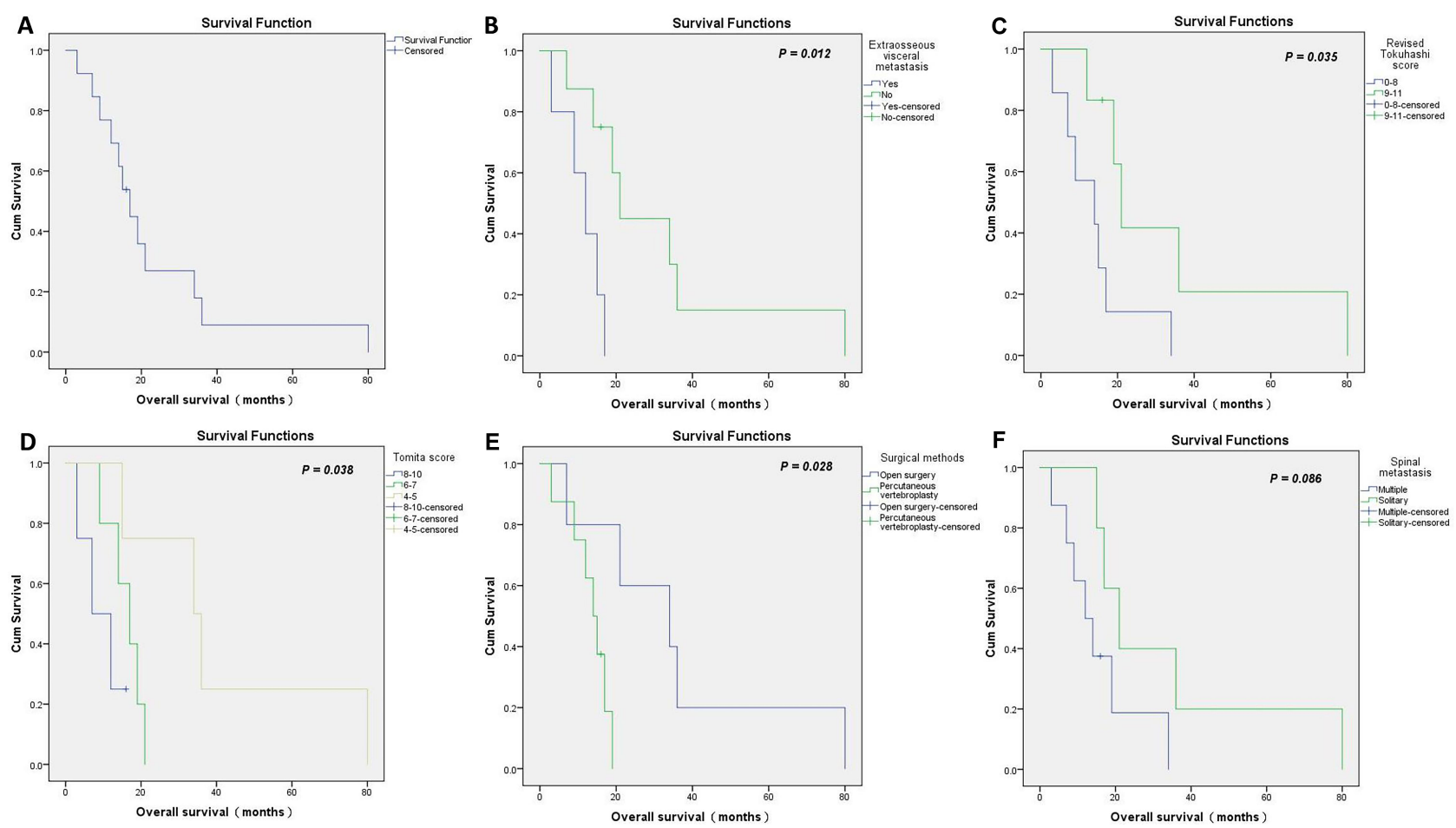

Figure 3 (A) Overall survival of all patients enrolled in our study. (B-F) Univariate analysis of prognostic factors significantly affecting overall survival.

A

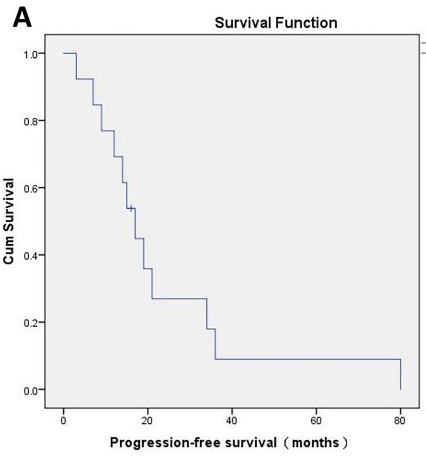

D

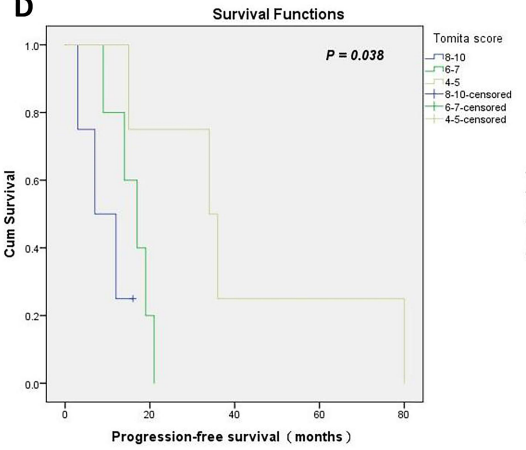

B

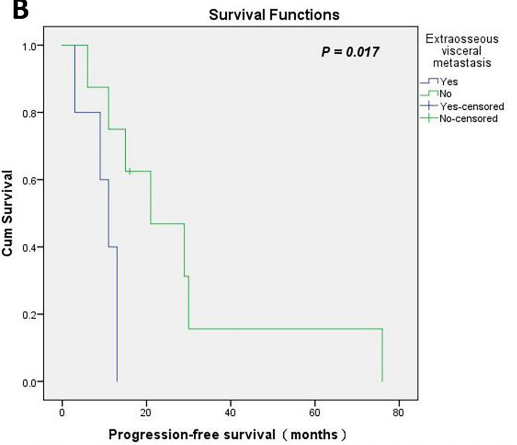

E

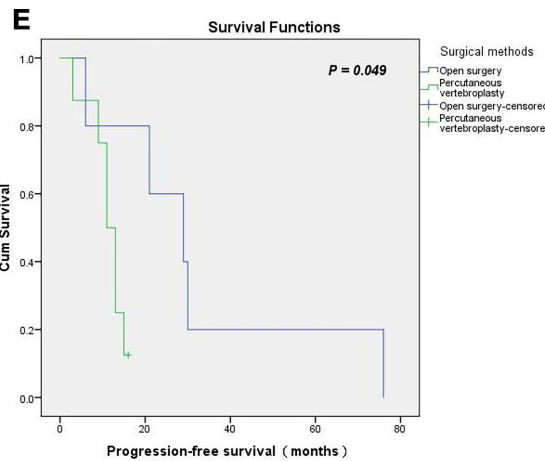

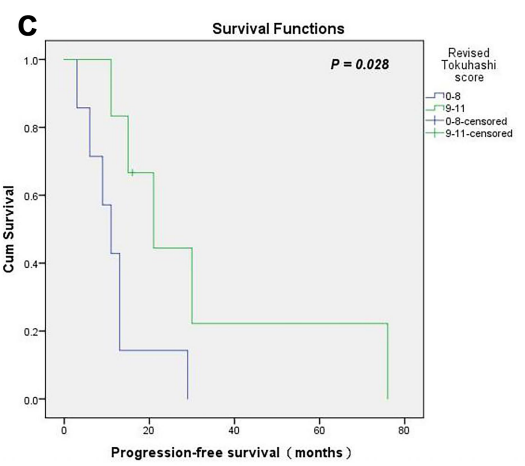

$\mathbf{F}$

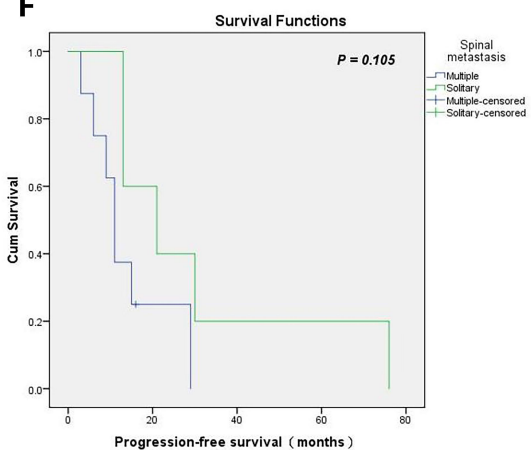

Figure 4 (A) Progression-free survival of all patients enrolled in our study. (B-F) Univariate analysis of prognostic factors significantly affecting progression-free survival.

a reliable independent prognostic factor. ${ }^{25,26}$ It is also suitable for most patients who are sensitive to radiation iodine therapy. External beam radiation therapy (EBRT) is also suitable for patients who are insensitive to ${ }^{131} \mathrm{I}$, have incomplete surgery, distant metastases and are elderly. ${ }^{27,28}$ Bisphosphonates effectively reduce skeletal-related events 
(SREs) such as pain, spinal cord compression, pathological fractures, and hypercalcemia; however, their effects are based on the initial occurrence time and number of SREs. ${ }^{29}$ Orita et al reviewed 50 patients with DTC bone metastases and found that $14 \%$ of patients receiving zoledronic acid had SREs, which was significantly fewer than those who did not receive treatment $(50 \% ; \mathrm{p}<0.05) .{ }^{30}$ However, the optimal dose of zoledronic acid is still under evaluation.

The prognosis of patients with DTC is generally good, but in the case of MSDTC, the quality of life and survival time can be significantly reduced. Therefore, it is of great clinical significance to apply active treatment measures to patients with MSDTC. ${ }^{1,9,10}$ In addition, an optimized treatment plan has not yet been identified due to the refractory nature of MSDTC. We conducted a more comprehensive study to reveal the factors that impact prognosis, and to allow appropriate comprehensive treatment that may improve quality of life and prolong survival. In our study, 10 patients $(90.9 \%)$ underwent thyroid cancer resection before spinal surgery. The average OS time of the 11 patients with MSDTC after surgery was 21.8 months (range 3-80) and the average PFS was 19.5 months (range 3-76). The 1-year and 2-year survival rates were $81.8 \%$ and $27.3 \%$, respectively. Kaplan-Meier survival analysis showed that extraosseous visceral metastasis $(\mathrm{p}=0.012)$, revised Tokuhashi score $(\mathrm{p}=0.035)$, Tomita score $(\mathrm{p}=0.038)$ and surgical method $(\mathrm{p}=0.028)$ were associated with OS. In addition, extraosseous visceral metastasis $(\mathrm{p}=0.017)$, revised Tokuhashi score $(\mathrm{p}=0.028)$, Tomita score $(\mathrm{p}=0.038)$, and surgical method $(\mathrm{p}=0.049)$ were associated with PFS. The results of our research have important significance for the guidance of clinical decisions in relation to the treatment and prognostic evaluation of patients with MSDTC.

This study is a retrospective analysis and is limited by the number of cases and therefore, a more systematic and comprehensive statistical analysis is not possible. In addition, this study was restricted to MSDTC patients who received surgical treatment leading to some selection bias. However, this study represents one of the largest single-center retrospective studies of surgical treatment of MSDTC patients in Asia. Therefore, the surgical and clinical data has relevance for the guidance of clinical decisions. In the future, multi-institutional studies should be considered to enhance statistical capabilities and clarify the prognostic factors related to MSDTC more clearly.

\section{Conclusions}

The optimal treatment of MSDTC requires multidisciplinary cooperation and multifactorial treatment including surgery, radiotherapy, chemotherapy, radioactive iodine $\left({ }^{131} \mathrm{I}\right)$, bisphosphonate and other new therapies. There is currently no international consensus on the optimal treatment or prognostic evaluation of patients with MSDTC although importantly, surgical treatment can effectively improve quality of life and prognosis. Improved knowledge of clinical characteristics and prognostic factors associated with MSDTC will be helpful to formulate effective clinical treatment plans to improve the quality of life and prognosis.

\section{Data Sharing Statement}

The anonymized data used and/or analyzed during the current study are available from the corresponding author (Yong Liu) on reasonable request.

\section{Ethics Approval and Consent to Participate}

This study was conducted with approval from the Ethics Committee of Peking Union Medical College Hospital. This study was conducted in accordance with the declaration of Helsinki. All patients have provided written informed consent for the case details to be published and all patients provided informed consent to have their medical records reviewed for this study.

\section{Consent for Publication}

Consent for publication was obtained from each patient.

\section{Acknowledgments}

We would like to thank our colleagues at the Departments of General surgery, Anesthesiology, Pathology, Nuclear medicine, Radiology, and Orthopaedic surgery for their support.

\section{Author Contributions}

All authors made a significant contribution to the work reported, whether that is in the conception, study design, execution, acquisition of data, analysis and interpretation, or in all these areas; took part in drafting, revising or critically reviewing the article; gave final approval of the version to be published; have agreed on the journal to which the article has been submitted; and agree to be accountable for all aspects of the work. 


\section{Funding}

This study was supported by Peking Union Medical College Graduate Student Innovation Fund (2018) (Project No. 2018-1002-02-08; Grant recipient: S.L.). The funder had no role in study design, data collection and analysis, decision to publish, or preparation of the manuscript.

\section{Disclosure}

The authors declare that they have no competing interests.

\section{References}

1. Bernstein MB, Chang EL, Amini B, et al. Spine stereotactic radiosurgery for patients with metastatic thyroid cancer: secondary analysis of Phase I/II trials. Thyroid. 2016;26(9):1269-1275.

2. Ramadan S, Ugas MA, Berwick RJ, et al. Spinal metastasis in thyroid cancer. Head Neck Oncol. 2012;4(1):39. doi:10.1186/1758-3284-4-39

3. Sellin JN, Suki D, Harsh V, et al. Factors affecting survival in 43 consecutive patients after surgery for spinal metastases from thyroid carcinoma. J Neurosurg Spine. 2015;23(4):419-428. doi:10.3171/ 2015.1.SPINE14431

4. Abrams HL, Spiro R, Goldstein N. Metastases in carcinoma; analysis of 1000 autopsied cases. Cancer. 1950;3(1):74-85.

5. Coleman RE. Clinical features of metastatic bone disease and risk of skeletal morbidity. Clin Cancer Res. 2006;12(20):6243s-6249s. doi:10.1158/1078-0432.CCR-06-0931

6. Durante C, Haddy N, Baudin E, et al. Long-term outcome of 444 patients with distant metastases from papillary and follicular thyroid carcinoma: benefits and limits of radioiodine therapy. J Clin Endocrinol Metab. 2006;91(8):2892-2899. doi:10.1210/jc.2005-2838

7. Fornasier VL, Horne JG. Metastases to the vertebral column. Cancer. 1975;36(2):590-594.

8. Bernier MO, Leenhardt L, Hoang C, et al. Survival and therapeutic modalities in patients with bone metastases of differentiated thyroid carcinomas. J Clin Endocrinol Metab. 2001;86(4):1568-1573. doi: $10.1210 /$ jcem.86.4.7390

9. Demura S, Kawahara N, Murakami H, et al. Total en bloc spondylectomy for spinal metastases in thyroid carcinoma. J Neurosurg Spine. 2011;14(2):172-176. doi:10.3171/2010.9.SPINE09878

10. Zhang D, Yin H, Wu Z, et al. Surgery and survival outcomes of 22 patients with epidural spinal cord compression caused by thyroid tumor spinal metastases. Eur Spine J. 2013;22(3):569-576. doi:10.1007/s00586-012-2534-2

11. Orita Y, Sugitani I, Matsuura M, et al. Prognostic factors and the therapeutic strategy for patients with bone metastasis from differentiated thyroid carcinoma. Surgery. 2010;147(3):424-431. doi:10. 1016/j.surg.2009.10.009

12. National Comprehensive Cancer Network. NCCN clinical practice guidelines in oncology thyroid carcinoma[M]. Version 2. NCCN.org; 2013:19-37.

13. Sciubba DM, Petteys RJ, Dekutoski MB, et al. Diagnosis and management of metastatic spine disease. A review. J Neurosurg Spine. 2010;13(1):94-108. doi:10.3171/2010.3.SPINE09202
14. Freudenberg LS, Antoch G, Jentzen W, et al. Value of (124) I-PET/ $\mathrm{CT}$ in staging of patients with differentiated thyroid cancer. Eur Radiol. 2004;14(11):2092-2098. doi:10.1007/s00330-004-2350-0

15. Xu JY, Murphy WJ, Milton DR, et al. Bone metastases and skeletal-related events in medullary thyroid carcinoma. $J$ Clin Endocrinol Metab. 2016;101(12):4871-4877. doi:10.1210/jc.2016-2815

16. Slook O, Levy S, Slutzky-Shraga I, et al. Long-term outcomes and prognostic factors in patients with differentiated thyroid carcinoma and bone metastases. Endocr Pract. 2019;25(5):427-437. doi:10. 4158/EP-2018-0465

17. Malik N, Nikitski AV, Klam E, et al. Molecular profile and clinical outcomes in differentiated thyroid cancer patients presenting with bone metastasis. Endocr Pract. 2019;25(12):1255-1262. doi:10.41 58/EP-2019-0265

18. Jiang L, Ouyang H, Liu X, et al. Surgical treatment of 21 patients with spinal metastases of differentiated thyroid cancer. Chin Med J. 2014;127(23):4092-4096.

19. Muresan MM, Olivier P, Leclere J, et al. Bone metastases from differentiated thyroid carcinoma. Endocr Relat Cancer. 2008;15 (1):37-49. doi:10.1677/ERC-07-0229

20. Quan GM, Pointillart V, Palussiere J, et al. Multidisciplinary treatment and survival of patients with vertebral metastases from thyroid carcinoma. Thyroid. 2012;22(2):125-130. doi:10.1089/thy.2010.0248

21. Matsumoto M, Tsuji T, Iwanami A, et al. Total en bloc spondylectomy for spinal metastasis of differentiated thyroid cancers: a long-term follow-up. J Spinal Disord Tech. 2013;26(4):E137-42. doi:10.1097/BSD.0b013e318278c8e4

22. Marcocci C, Pacini F, Elisei R, et al. Clinical and biologic behavior of bone metastases from differentiated thyroid carcinoma. Surgery. 1989;106(6):960-966.

23. Mendel E, Bourekas E, Gerszten P, et al. Percutaneous techniques in the treatment of spine tumors: what are the diagnostic and therapeutic indications and outcomes? Spine. 2009;34(22 Suppl):S93-100. doi:10.1097/BRS.0b013e3181b77895

24. Song HJ, Wu CG, Xue YL, et al. Percutaneous osteoplasty combined with radioiodine therapy as a treatment for bone metastasis developing after differentiated thyroid carcinoma. Clin Nucl Med. 2012;37 (6):e129-33. doi:10.1097/RLU.0b013e31824786d0

25. Wexler JA. Approach to the thyroid cancer patient with bone metastases. J Clin Endocrinol Metab. 2011;96(8):2296-2307. doi:10.1210/jc.2010-1996

26. Pittas AG, Adler M, Fazzari M, et al. Bone metastases from thyroid carcinoma: clinical characteristics and prognostic variables in one hundred forty-six patients. Thyroid. 2000;10(3):261-268. doi:10.1089/thy.2000.10.261

27. Itshayek E, Yamada J, Bilsky M, et al. Timing of surgery and radiotherapy in the management of metastatic spine disease: a systematic review. Int J Oncol. 2010;36(3):533-544.

28. Laufer I, Iorgulescu JB, Chapman T, et al. Local disease control for spinal metastases following "separation surgery" and adjuvant hypofractionated or high-dose single-fraction stereotactic radiosurgery: outcome analysis in 186 patients. J Neurosurg Spine. 2013;18 (3):207-214. doi:10.3171/2012.11.SPINE12111

29. Farooki A, Leung V, Tala H, et al. Skeletal-related events due to bone metastases from differentiated thyroid cancer. $J$ Clin Endocrinol Metab. 2012;97(7):2433-2439. doi:10.1210/jc.2012-1169

30. Orita Y, Sugitani I, Toda K, et al. Zoledronic acid in the treatment of bone metastases from differentiated thyroid carcinoma. Thyroid. 2011;21(1):31-35. doi:10.1089/thy.2010.0169 


\section{Publish your work in this journal}

Cancer Management and Research is an international, peer-reviewed open access journal focusing on cancer research and the optimal use of preventative and integrated treatment interventions to achieve improved outcomes, enhanced survival and quality of life for the cancer patient.
The manuscript management system is completely online and includes a very quick and fair peer-review system, which is all easy to use. Visit http://www.dovepress.com/testimonials.php to read real quotes from published authors.

Submit your manuscript here: https://www.dovepress.com/cancer-management-and-research-journal 